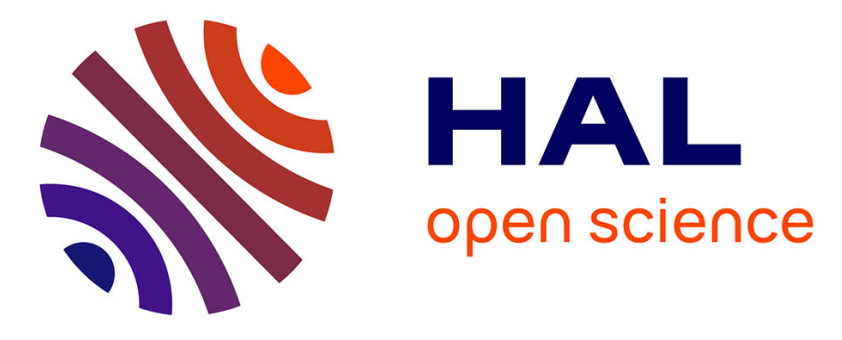

\title{
Oxidation of Si nanocrystals fabricated by ultralow-energy ion implantation in thin $\mathrm{SiO} 2$ layers
}

H. Coffin, Caroline Bonafos, Sylvie Schamm-Chardon, Nikolay Cherkashin, Gérard Benassayag, Alain Claverie, Marc Respaud, P. Dimitrakis, P. Normand

\section{- To cite this version:}

H. Coffin, Caroline Bonafos, Sylvie Schamm-Chardon, Nikolay Cherkashin, Gérard Benassayag, et al.. Oxidation of Si nanocrystals fabricated by ultralow-energy ion implantation in thin SiO2 layers . Journal of Applied Physics, 2006, 99 (4), pp.044302. 10.1063/1.2171785 . hal-01736074

\section{HAL Id: hal-01736074 \\ https://hal.science/hal-01736074}

Submitted on 23 Mar 2018

HAL is a multi-disciplinary open access archive for the deposit and dissemination of scientific research documents, whether they are published or not. The documents may come from teaching and research institutions in France or abroad, or from public or private research centers.
L'archive ouverte pluridisciplinaire HAL, est destinée au dépôt et à la diffusion de documents scientifiques de niveau recherche, publiés ou non, émanant des établissements d'enseignement et de recherche français ou étrangers, des laboratoires publics ou privés. 


\section{Oxidation of Si nanocrystals fabricated by ultralow-energy ion implantation in thin $\mathrm{SiO}_{2}$ layers}

H. Coffin, C. Bonafos, S. Schamm, N. Cherkashin, G. Ben Assayag, A. Claverie, M. Respaud, P. Dimitrakis, and P. Normand

Citation: Journal of Applied Physics 99, 044302 (2006); doi: 10.1063/1.2171785

View online: https://doi.org/10.1063/1.2171785

View Table of Contents: http://aip.scitation.org/toc/jap/99/4

Published by the American Institute of Physics

\section{Articles you may be interested in}

Modeling stress retarded self-limiting oxidation of suspended silicon nanowires for the development of silicon nanowire-based nanodevices

Journal of Applied Physics 110, 033524 (2011); 10.1063/1.3611420

General Relationship for the Thermal Oxidation of Silicon

Journal of Applied Physics 36, 3770 (1965); 10.1063/1.1713945

Plastic analysis of cylinder oxidation

Applied Physics Letters 54, 1815 (1989); 10.1063/1.101248

Thermal oxidation of silicon nanocrystals in $\mathrm{O}_{2}$ and $\mathrm{NO}$ ambient Journal of Applied Physics 93, 5637 (2003); 10.1063/1.1565172

Oxidation property of silicon small particles

Applied Physics Letters 58, 1662 (1991); 10.1063/1.105129

Self-limiting oxidation for fabricating sub- $5 \mathrm{~nm}$ silicon nanowires

Applied Physics Letters 64, 1383 (1994); 10.1063/1.111914

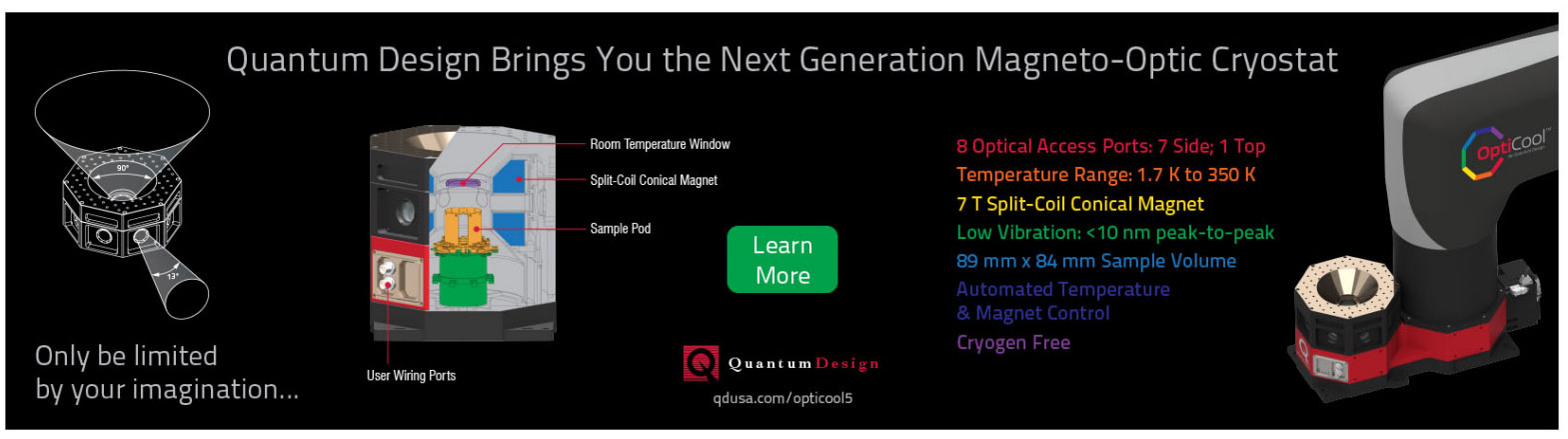




\title{
Oxidation of Si nanocrystals fabricated by ultralow-energy ion implantation in thin $\mathrm{SiO}_{2}$ layers
}

\author{
H. Coffin, C. Bonafos, ${ }^{\text {a) }}$ S. Schamm, N. Cherkashin, ${ }^{\text {b) }}$ G. Ben Assayag, and A. Claverie \\ CEMES-CNRS, 29 rue J. Marvig, 31055 Toulouse, France \\ M. Respaud \\ LNMO, INSA, Département de Physique, 135 Avenue de Rangueil, 31077 Toulouse, France \\ P. Dimitrakis and P. Normand \\ Institute of Microelectronics, NCSR “Demokritos," 15310 Aghia Praskevi, Greece
}

(Received 29 July 2005; accepted 10 January 2006; published online 16 February 2006)

\begin{abstract}
The effect of thermal treatments in nitrogen-diluted oxygen on the structural characteristics of two-dimensional arrays of Si nanocrystals (NCs) fabricated by ultralow-energy ion implantation (1 $\mathrm{keV}$ ) in thin silicon dioxide layers is reported. The NC characteristics (size, density, and coverage) have been measured by spatially resolved electron-energy-loss spectroscopy by using the spectrum-imaging mode of a scanning transmission electron microscope. Their evolution has been studied as a function of thermal treatment duration at a temperature $\left(900{ }^{\circ} \mathrm{C}\right)$ below the $\mathrm{SiO}_{2}$ viscoelastic point. An extended spherical Deal-Grove [J. Appl. Phys. 36, 3770 (1965)] model for self-limiting oxidation of embedded silicon NCs has been carried out. It proposes that the stress effects, due to oxide deformation, slow down the $\mathrm{NC}$ oxidation rate and lead to a self-limiting oxide growth. The model predictions show a good agreement with the experimental results. Soft oxidation appears to be a powerful way for manipulating the NC size distribution and surface density. () 2006 American Institute of Physics. [DOI: 10.1063/1.2171785]
\end{abstract}

\section{INTRODUCTION}

A nanocrystal (NC) memory cell consists of a metaloxide-semiconductor field-effect transistor (MOSFET) with monodisperse nanometer-scale crystals embedded within the gate dielectric. ${ }^{1}$ By associating the finite-size effects of NCs and the benefits (robustness and fault tolerance) of a stored charge distribution, $\mathrm{NC}$ memories offer an attractive alternative for extending the scaling of conventional floating-gate memories (e.g., flash nonvolatile memories). Various NC materials and NC self-assembling techniques have been explored in the last few years. A substantial amount of investigation has gone into $\mathrm{Si}, \mathrm{Ge}$, or $\mathrm{SiGe}$ materials using different deposition techniques, ${ }^{1,2}$ thermal oxidation of $\mathrm{Si}_{1-x} \mathrm{Ge}_{x},{ }^{3}$ or ion implantation followed by annealing. ${ }^{4,5}$ The possibility of fabricating $\mathrm{Si} \mathrm{NCs}$ in thin $\mathrm{SiO}_{2}$ films by ultralow-energy $\mathrm{Si}$ implantation and subsequent thermal treatment has been recently demonstrated. ${ }^{6,7}$ This fabrication route is very attractive because of its ability to control the size and location of a narrow $\mathrm{NC}$ band and its compatibility with standard complementary metal-oxide semiconductor (CMOS) processes. In practice, high-dose (typically $\left.10^{16} \mathrm{~cm}^{-2}\right) \mathrm{Si}$ implantation in the $1 \mathrm{keV}$ range into very thin $(<10 \mathrm{~nm})$ oxide layers followed by annealing at temperatures in the $900-1000{ }^{\circ} \mathrm{C}$ range allows for the formation of two-dimensional (2D) arrays of $\mathrm{Si} \mathrm{NCs}$ at tunable tunneling distances from the $\mathrm{SiO}_{2} / \mathrm{Si}$ interface. ${ }^{6}$ As shown in Ref. 7, it is possible to accurately control the position of the NC band by changing the

\footnotetext{
a) Author to whom correspondence should be addressed; electronic mail: bonafos@cemes.fr

b) On leave from Ioffe Physico-Technical Institute, St. Petersburg 194021, Russia.
}

implantation and annealing conditions. In addition, Si-NC gate stacks with improved electrical performance have been obtained recently by carrying out the annealing step under slight oxidizing conditions. ${ }^{8}$ Such conditions restore significantly the integrity of the oxide and lead to gate stacks suitable for nonvolatile memory devices operating at low voltages. ${ }^{9}$ Annealing in oxidizing conditions affects also the $\mathrm{NC}$ population. ${ }^{10}$ As a consequence the oxidation step can be used for monitoring the size, density, and surface fraction of the NC population and thus for controlling the memory performance of the final devices. It is expected that below the viscoelastic temperature of $\mathrm{SiO}_{2}\left(950^{\circ} \mathrm{C}\right),{ }^{11,12}$ the oxidation of nonplanar $\mathrm{Si}$ structures is retarded due to normal stress induced at the $\mathrm{Si} / \mathrm{SiO}_{2}$ interface, ${ }^{13-16}$ thus leading to selflimiting size effects. The aim of this work is to study and model the thermal oxidation of $\mathrm{Si} \mathrm{NCs}$ embedded in $\mathrm{SiO}_{2}$. $\mathrm{NC}$ oxidation is examined as a function of the duration of thermal treatments performed at $900{ }^{\circ} \mathrm{C}$ in nitrogen-dilutedoxygen ambient $\left(\mathrm{N}_{2}+1.5 \% \mathrm{O}_{2}\right)$. The $\mathrm{NC}$ characteristics (size and aerial density) have been extracted from filtered images obtained by using the spectrum-imaging mode of a scanning transmission electron microscope (STEM). The swelling of the $\mathrm{SiO}_{2}$ layer due to $\mathrm{NC}$ oxidation has been measured on cross-sectional transmission electron microscopy (TEM) images. In addition, we have extended the onedimensional (1D) Deal and Grove model ${ }^{17}$ to spherical geometry in order to properly model the Si NC evolution under oxidation. This model assumes that stress effects associated with nonuniform deformation of the oxide by viscous flow reduce the oxidation rate. Based on the work of Kao et $a l .{ }^{13,14}$ and Omachi et al., ${ }^{16}$ it predicts the retardation of oxide growth on a curved surface. This retardation effect in- 
creases when the NC size decreases, leading to a selflimiting oxide growth. The model predictions show a good agreement with the experimental results.

\section{EXPERIMENTAL DETAILS AND METHODS}

Silicon dioxide layers of $7 \mathrm{~nm}$ in thickness were thermally grown by dry oxidation on 8-in., p-type, (100)oriented Si wafers, and subsequently implanted with $1 \mathrm{keV}$ ${ }^{28} \mathrm{Si}$ ions to a dose of $10^{16} \mathrm{Si}^{+} \mathrm{cm}^{-2}$ using an AXCELIS GDS-ULTRA implanter. Then, the implanted samples were cleaned using a piranha solution, annealed for $30 \mathrm{~min}$ at $1050{ }^{\circ} \mathrm{C}$ under $\mathrm{N}_{2}$ for the purpose of $\mathrm{NC}$ formation, and thermal oxidized under $\mathrm{N}_{2}+1.5 \% \quad \mathrm{O}_{2}$ at $900{ }^{\circ} \mathrm{C}$ for different times (from 5 to $240 \mathrm{~min}$ ). Cross-sectional and plan-view TEM specimens were prepared by the standard procedures of grinding, dimpling, and $\mathrm{Ar}^{+}$-ion-beam thinning. Due to the small difference in atomic number and density between $\mathrm{Si}$ and $\mathrm{SiO}_{2}$, the NCs show a weak amplitude and phase contrast by TEM. Size distribution can be measured on highresolution electron microscopy (HREM) images or by using dark-field conditions, but as these images are orientation dependent, the direct measurement of the NC surface density is impossible. Therefore, the Si NCs were imaged on a planview specimen by performing parallel electron-energy-loss spectroscopy (PEELS) in a scanning transmission electron microscope, VG-HB 501 operating at $100 \mathrm{kV}$, using the spectrum-image technique (called PEELS-STEM in the following). ${ }^{18}$ This microscope is equipped with a fieldemission cathode and a parallel Gatan 666 EELS spectrometer. The EELS spectra were recorded over the first $50 \mathrm{eV}$ on each image point of the specimen (typically $256 \times 256$ ). The EELS experiment is performed in the low-energy-loss domain. Plasmons, corresponding to plasma oscillations of valence electrons associated with each phase of the analyzed area, are the major signatures in this energy domain of the EELS spectra. Bulk silicon and silica plasmons are located at 17 and $23.5 \mathrm{eV}$, respectively. They are well separated and thus can be used to get the image associated with the corresponding phase. After acquisition of a spectrum at each point of the image, contributions from silicon plasmon and silica plasmon are isolated by reconstruction of the signal with reference spectra of $\mathrm{Si}$ and silica. Then a map can be displayed where the gray levels are defined by the weight of $\mathrm{Si}$ deduced from the reconstruction parameters. On such "chemical images," all the Si NCs are visible, amorphous, eith crystalline, and in the last case whatever their orientation is. A contrast enhancement method is applied to these images in order to perform quantitative measurements such as the NC mean size and aerial density and surface fraction and number of atoms stored within the NCs. In order to control the homogeneity of the NC distribution throughout the planview TEM samples, energy filtering transmission electron microscopy (EFTEM) experiments have also been performed for particular samples. By inserting an energy-selecting slit in the energy-dispersive plane of the filter at the Si plasmon energy, the population of Si NCs can also be visualized. A TEM-FEG microscope, Tecnai F20ST equipped with an energy filter, TRIDIEM from Gatan was used. The contrast in the EFTEM raw images is less than in the PEELS-STEM technique because there is a contribution of the silica plasmon signal at the plasmon energy of Si. However, after applying the contrast enhancement method, the two types of images became comparable.

Cross-sectional TEM (XTEM) studies were carried out using a CM30 Philips TEM equipped with $\mathrm{a} \mathrm{LaB}_{6}$ cathode operating at $300 \mathrm{kV}$ and having a nominal resolution of 0.19 $\mathrm{nm}$. These observations aim at measuring the depth position of the $\mathrm{NC}$ layer in the $\mathrm{SiO}_{2}$ layer and, in particular, the location of the NCs in respect to the Si substrate and the surface. For this, we have developed a method for fast and accurate distance measurements using Fresnel contrast. ${ }^{19}$ As mentioned earlier, the difference between the mean atomic numbers and the densities in $\mathrm{Si}$ and $\mathrm{SiO}_{2}$ are small so the $\mathrm{Si}$ NCs show no amplitude contrast when buried in a $\mathrm{SiO}_{2}$ layer. Nevertheless, the electrostatic potentials being slightly different in $\mathrm{Si}$ and $\mathrm{SiO}_{2}$, some small phase shift exists between electron waves having propagated or not through the NC layer. This phase shift can be "imaged" by using strongly defocused bright-field conditions, provided the incident beam is highly coherent. Under such conditions, a pair of (black/white or white/black) Fresnel fringes appears exactly centered on each interface. Microdensitometric analysis of such images can be performed using an online chargecoupled device (CCD) camera and image processing facilities so that averaging of the gray levels along the direction perpendicular to the layers can be represented by a "line scan." Thus, on such experimental densitometric profiles, all the distances of interest can be precisely measured by locating the inflexion points of each pair of black and white fringes originating from the different interfaces. The uncertainty of these distance measurements is estimated to be $\pm 0.5 \mathrm{~nm}$. Finally, a poly-Si layer has been deposited after annealing on top of the samples in order to facilitate the distance measurement with respect to the surface.

\section{EXPERIMENTAL RESULTS}

As shown in Ref. 20 the NC characteristics strongly depend on the implanted dose. When implanting at $1 \mathrm{keV}$ no NCs are detected for doses below $5 \times 10^{15} \mathrm{~cm}^{-2}$, while a high dense array of spherelike NCs is formed at a medium dose $\left(10^{16} \mathrm{~cm}^{-2}\right)$ and a connected array of elongated NCs with a larger size and less density is formed at a highest dose $\left(2 \times 10^{16} \mathrm{~cm}^{-2}\right)$. In the last case, annealing under $\mathrm{N}_{2}+\mathrm{O}_{2}$ has been shown to be an efficient way for separating the connected NCs. ${ }^{21}$ In this work, we have chosen to study the oxidation process of $\mathrm{Si}$ NCs embedded in $\mathrm{SiO}_{2}$ in the case of the medium range fluence $\left(10^{16} \mathrm{~cm}^{-2}\right)$ for which a high density of well-separated spherical NCs is observed after annealing at $1050{ }^{\circ} \mathrm{C}$ for 30 min under $\mathrm{N}_{2}$ [see Fig. 1(a)]. After this high-temperature NC formation step, the NCs were oxidized at $900{ }^{\circ} \mathrm{C}$ for different durations (between 5 and $240 \mathrm{~min}$ ). As reported above, the oxidation temperature being above the viscoelastic temperature $\left[950{ }^{\circ} \mathrm{C}\right.$ for thermal $\mathrm{SiO}_{2}$ (Refs. 11 and 12)], a self-limiting oxidation process is expected. ${ }^{22,23}$ As it appears in the PEELS-STEM images of Fig. 1 and on the graph shown in Fig. 2(a), the average size of the NCs 


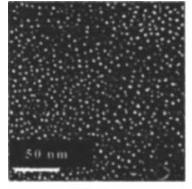

(a)

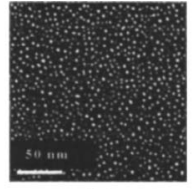

(b)

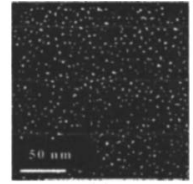

(c)

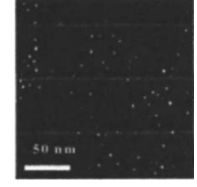

(d)
FIG. 1. Plan-view PEELS-STEM images of (a) reference sample $\left(\mathrm{N}_{2}\right)$; [(b)(d)] oxidized samples after 5, 30, and $240 \mathrm{~min}$, respectively. The contrast of the original images has been enhanced.

(square symbols) slowly decreases from $2.9 \pm 0.3 \mathrm{~nm}$ for the reference sample $\left(\mathrm{N}_{2}, 1050{ }^{\circ} \mathrm{C}, 30 \mathrm{~min}\right)$ to $1.8 \pm 0.2 \mathrm{~nm}$ for a sample annealed under $\mathrm{N}_{2}+\mathrm{O}_{2}$ during $240 \mathrm{~min}$. Meanwhile, the NC density [see Fig. 2(b)] decreases by a factor of 10 . Thus, the surface fraction (coverage) decreases from $12 \%$ after $5 \mathrm{~min}$ to $1 \%$ after $240 \mathrm{~min}$ of annealing [see Fig. 3(a)]. This corresponds to a decrease of the number of Si atoms by a surface unit contained within the NCs from $1.4 \times 10^{15}$ to $10^{14}$ at. $\mathrm{cm}^{2}$ [see Fig. 3(b)], indicating that the progressive oxidation of the nanoclusters takes place. As we can see in Figs. 2 and 3, this evolution takes place following two stages. During the first $60 \mathrm{~min}$ the size and NC density linearly decrease and then, for longer annealing times, the consumption of silicon slows down and stabilizes.

XTEM observations (see Fig. 4) have allowed the measurement of the different characteristic distances- $-\mathrm{SiO}_{2}$ thickness $\left(e_{\mathrm{SiO}_{2}}\right)$, injection distance $\left(d_{\text {inj }}, \mathrm{SiO}_{2}\right.$ thickness between the $\mathrm{Si} / \mathrm{SiO}_{2}$ interface and the $\mathrm{NC}$ layer), width of the NC layer $\left(e_{\mathrm{ncs}}\right)$, and gate distance $\left(d_{\mathrm{gate}}, \mathrm{SiO}_{2}\right.$ thickness between the $\mathrm{NC}$ layer and the $\mathrm{SiO}_{2}$ surface) - by using the method described in Ref. 19. The cross-sectional scheme in Fig. 5 shows the quantitative evolution of these distances $(x$ axis) for different annealing durations ( $y$ axis). As we can see in Fig. 5, the width of the NC layer slightly decreases with an increase of the annealing time under $\mathrm{N}_{2}+\mathrm{O}_{2}$. For oxidation duration larger than $30 \mathrm{~min}$, the contrast of the $\mathrm{NC}$ layer is very weak, due to the small density of particles, and the evaluation of the NC layer width is no more possible. On the other hand, the whole oxide thickness increases when increasing the oxidation duration (from $10.4 \pm 0.5$ initially to $13.2 \pm 0.5 \mathrm{~nm}$ after $240 \mathrm{~min})$. It is important to point out that this swelling concerns both the control and the injection oxide: the $\mathrm{SiO}_{2} / \mathrm{Si}$ interface is therefore also oxidized in addition to the NCs.
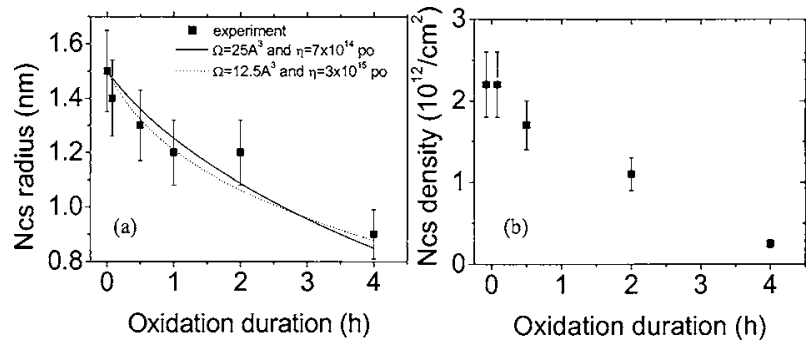

FIG. 2. Evolution of (a) the Si NC mean radius and (b) of the NC aerial density vs annealing time under $\mathrm{N}_{2}+\mathrm{O}_{2}$, as measured on the images in Fig. 1. In (a) the model predictions for $\Omega=25 \AA^{3}$ and $\Omega=12.5 \AA^{3}$ are plotted in the solid and dashed lines, respectively.
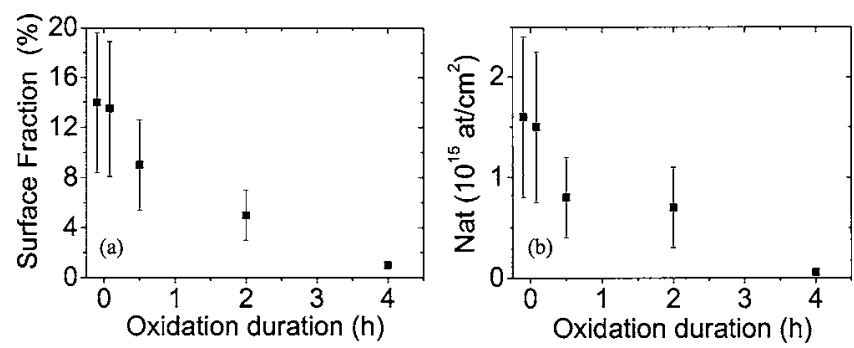

FIG. 3. Evolution of (a) the percentage of surface occupied by Si NCs (coverage) and (b) of the number of silicon atoms within the NCs vs the annealing time under $\mathrm{N}_{2}+\mathrm{O}_{2}$, deduced from the images in Fig. 1.

\section{MODELING OF THE SI NANOCRYSTAL OXIDATION}

The most comprehensive characterization of the stress effects during oxidation of nonplanar Si structures was performed by Kao et al. ${ }^{13,14}$ These authors have extended the one-dimensional stress-free model of Deal and Grove ${ }^{17}$ to the oxidation of nonplanar silicon structures, i.e., to concave and convex cylindrical 2D structures. For this, they treated the oxide as an incompressible viscous fluid being driven by a velocity field at the silicon/oxide interface.

This assumption $\left(\mathrm{SiO}_{2}\right.$ is a viscous fluid) is, in fact, valid above the viscous flow point $\left(950{ }^{\circ} \mathrm{C}\right)$, while at low temperatures (below $800{ }^{\circ} \mathrm{C}$ ) $\mathrm{SiO}_{2}$ behaves as an elastic solid. ${ }^{11,12}$ Between these extremes, it presents more complex mechanical characteristics and for modeling stress effects during nonplanar oxidation, several authors have considered a viscoelastic behavior, which mixes both reversible elastic deformation and steady flow process. ${ }^{24}$

A further improvement of the modeling of stress effects in silicon oxidation led to the introduction of shear-stressdependent viscosity. ${ }^{24-26}$ This stress effect is, in fact, similar to a plastic phenomenon and gives a nonlinear behavior to the material. Indeed, it is known from the experiment that $\mathrm{SiO}_{2}$ becomes more fluidic under a high stress state, ${ }^{27}$ leading to a strong modification of its viscosity. The lowered viscosity at a high stress level results in a slower increase of the oxide stress when increasing the interfacial curvature than would otherwise occur. Plasticity has been incorporated in both viscoelastic and viscous formulations. ${ }^{24-26,28}$ For 2D cylinders, it has been shown that linear viscous models usually overpredict the stress by two orders of magnitude at low temperature even if the viscoelastic solution approaches the plastic solution at high temperature. ${ }^{28}$ In addition, still for $2 \mathrm{D}$ structures, the linear viscous flow models generate stress values larger, especially at low temperatures, than the threshold value for plastic deformation (for $\mathrm{SiO}_{2} 10^{9} \mathrm{dyn} / \mathrm{cm}^{2}$, i.e., $\left.10^{8} \mathrm{~Pa}\right) .{ }^{28}$ At last, taking into account nonlinearity deformation has been proven to be crucial for the successful fitting of the experimental results for concave structures. ${ }^{25,26}$

In our experimental case (dry oxidation at $900{ }^{\circ} \mathrm{C}$ for

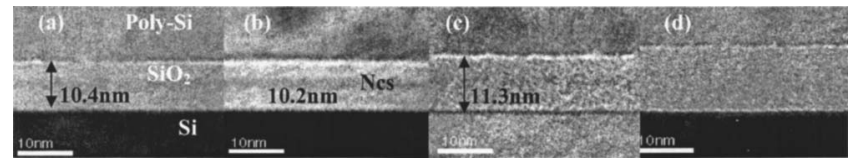

FIG. 4. XTEM images of (a) reference sample $\left(\mathrm{N}_{2}\right)$; [(b)-(d)] oxidized samples for 5, 30, and $240 \mathrm{~min}$, respectively. 


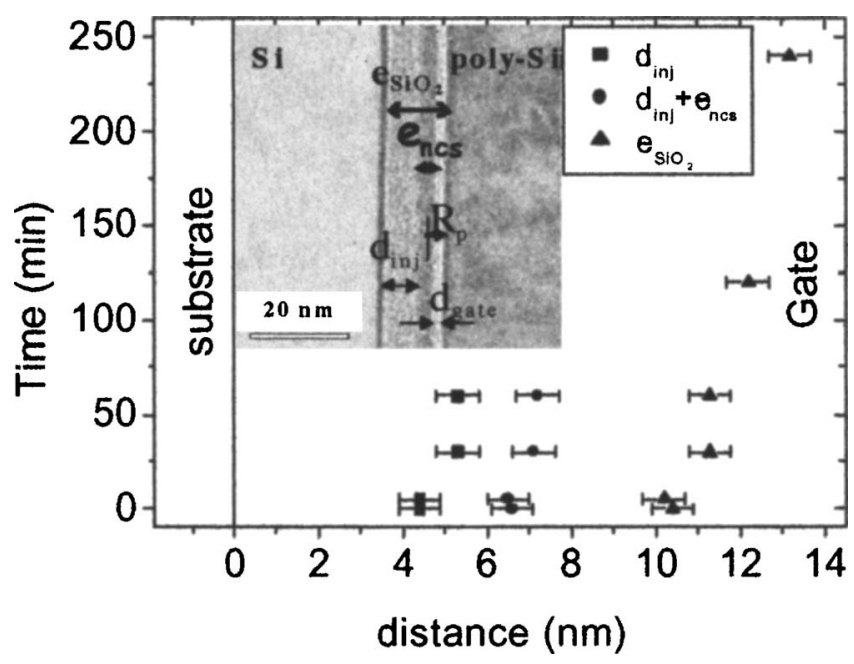

FIG. 5. Cross-sectional scheme depicting the evolution of the characteristic distances as a function of the oxidation duration, from 0 (reference sample) to $240 \mathrm{~min}$ at $900{ }^{\circ} \mathrm{C}$ ( $y$ axis). These distances were measured on the XTEM images of Fig. 4 and are plotted on the $x$ axis. Up triangles: distance between the bottom edge of the NC layer and the Si substrate (injection distance). Down triangles: distance between the top edge of the NC layer and the Si substrate. Squares: distance between the polysilicon layer and the $\mathrm{Si}$ substrate $\left(\mathrm{SiO}_{2}\right.$ thickness). All the distances are measured with an accuracy of $\pm 0.5 \mathrm{~nm}$. In the inset, a XTEM image is shown where all these distances are defined.

some hours) we have evaluated by a simple calculation the time for viscous flow to develop, that is, the time for the stress to reach the steady-state value. ${ }^{29}$ This time is, by using a linear model and viscosity values measured by Fargeix and Ghibaudo, ${ }^{30}$ of about $50 \mathrm{~min}$, i.e., smaller than the whole oxidation duration (some hours). As a consequence, we have assumed in our model a deformation of $\mathrm{SiO}_{2}$ by viscous flow. This assumption is in agreement with EerNisse's experimental measurements ${ }^{11}$ of diagnostics viscous flow of dry and wet $\mathrm{SiO}_{2}$ when annealing at $925^{\circ} \mathrm{C}$ for oxidation times larger than $20 \mathrm{~min}$. In addition, we have considered that the thermal budget $\left(900{ }^{\circ} \mathrm{C}\right.$ for some hours) was sufficiently high that we can neglect plastic deformation and assume linear deformation and a pressure-dependent viscosity, as described by Dane and Birch ${ }^{31}$ and not a shear-modulusdependent viscosity linked to plasticity effects. ${ }^{24-26}$ In other words, we treated the oxide as an incompressible viscous fluid as Kao et al. ${ }^{13,14}$ and Omachi et al. ${ }^{16}$ also did. The obtained stress levels will be discussed in Sec. V and compared to the threshold stress value for plastic deformation.

The 2D model of Kao et al., ${ }^{13,14}$ which concerns the micrometric concave and convex cylindrical structures under wet oxidation, has been extended to the three-dimensional (3D) spherical conditions by Chen and applied to nanocrystalline Si quantum dots under dry oxidation. ${ }^{15}$ To avoid a tedious fluid mechanics analysis of oxide stress, these authors have used an approximate scale analysis and assumed the influence of stress on the diffusion and solid solubility constant to be much less important than the influence on the chemical reaction rate. Omachi et al. ${ }^{16}$ have included these effects in their model. Nevertheless, their model implies not less than five fitting parameters and a good agreement with the experiment is obtained for values of the zero-pressure (a)

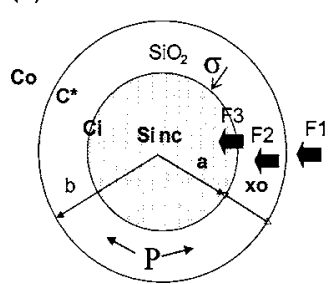

(b) Free surface

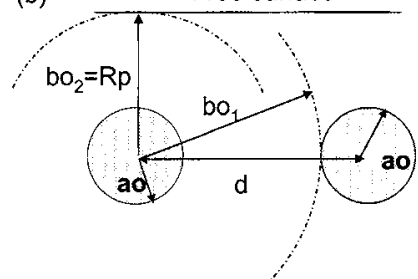

FIG. 6. Schematics of (a) a spherical Si NC surrounded by an oxide shell with normal compressive stress at the interface $(\sigma)$ and tensile stress (hydrostatic pressure, $P$ ) within the oxide volume, which appear during the viscous flow of the growing oxide and (b) of two neighboring NCs surrounded by their oxide shell.

viscosity of $10^{12}$ poises, i.e., three orders of magnitude less than measured at this temperature $\left(850^{\circ} \mathrm{C}\right)$ for dry oxidation. $^{30}$

To model the oxidation process of our system, i.e., $\mathrm{Si}$ NCs embedded within a thin $\mathrm{SiO}_{2}$ matrix, we have used the extension of the Deal and Grove model to 3D geometry of Omachi et al., ${ }^{16}$ implying both normal stress at the interface and hydrostatic pressure in the oxide volume. A particular attention has been paid in limiting the number of fitting parameters and in using realistic constants. This model predicts the evolution during annealing under oxidizing ambient of a $\mathrm{NC}$ with an initial size, the average radius of the NC population after the nucleation stage (reference sample).

Classically, the oxidation is divided into three processes which are associated with three fluxes [see Fig. 6(a) $].{ }^{17}$ The first flux $F_{1}$ concerns the diffusion of oxidizing species $\left(\mathrm{O}_{2}\right)$ at the gas/oxide interface, the second flux $F_{2}$ is associated with the diffusion of the oxidizing species into the $\mathrm{SiO}_{2}$, and the third flux $F_{3}$ represents the flux of oxidizing species at the $\mathrm{Si} / \mathrm{SiO}_{2}$ interface. These three fluxes can be expressed as

$$
\begin{aligned}
& F_{1}=h\left(C^{*}-C_{0}\right), \\
& F_{2}=-D \frac{d C}{d r}, \\
& F_{3}=k_{s} C_{i},
\end{aligned}
$$

where $h$ is the surface mass transfer constant of oxidant, $D$ is the diffusivity of oxidant in the $\mathrm{SiO}_{2}, k_{s}$ is the surface reaction rate constant at the $\mathrm{SiO}_{2} / \mathrm{Si}$ interface, $C^{*}$ is the oxidant solubility in $\mathrm{SiO}_{2}, C_{i}$ is the concentration of oxidant near the $\mathrm{Si} / \mathrm{SiO}_{2}$ interface, and $C_{0}$ is the concentration of the oxidant at the outer surface of the oxide.

In the Deal and Grove model, the three fluxes are set equal due to the steady-state condition. The steady-state diffusion equation inside the oxide is given by

$$
\nabla^{2} C=\frac{1}{r^{2}} \frac{\partial}{\partial r}\left(r^{2} \frac{\partial C}{\partial r}\right)=0 .
$$

The solution of this Laplace equation in spherical coordinates is a hyperbole fragment, $C(r)=A+B / r$. Considering that the mass transport is conserved for any radius $r$ and combining Eqs. (1)-(4) the oxidation rate for a spherical $\mathrm{Si}$ $\mathrm{NC}$ can be expressed as ${ }^{15,16}$ 


$$
\frac{d x}{d t}=\frac{1}{N} \frac{C^{*}}{1 / k_{s}+a^{2} / b^{2} h+a(b-a) / b D} .
$$

Instead of

$$
\frac{d x}{d t}=\frac{1}{N} \frac{C^{*}}{1 / k_{s}+1 / h+\left(1 / D_{0}\right)(b-a)}
$$

for planar oxidation. ${ }^{17} x=b-a$ with $a$ is the NC core radius and $b$ is the radius of the NC core plus oxide shell [see Fig. 6(a)], both varying with time. $N$ is the number of oxidant molecules incorporated into $\mathrm{SiO}_{2}$ per unit volume of oxide grown. $N=2.2 \times 10^{22}$ molecules $/ \mathrm{cm}^{3}$ for dry oxidation by considering that one $\mathrm{O}_{2}$ molecule is incorporated into each $\mathrm{SiO}_{2}$ molecule. Because of volume conservation, the $\mathrm{Si}$ core radius, $a$, and the core + shell radius, $b$, are not independent variables. ${ }^{15}$ We assume an incompressible fluidic oxide and the ratio of produced $\mathrm{SiO}_{2}$ volume to the consumed $\mathrm{Si}$ volume 2.25(=45/20): 1 . If the starting radius of $\mathrm{Si}$ core is $a_{0}$ and the starting radius of the core + shell sphere is $b_{0}$, the above assumption results in the following relation between $a$ and $b:^{15}$

$$
b^{3}+1.25 a^{3}=b_{0}^{3}+1.25 a_{0}^{3}=B .
$$

The evolution of the new NC radius $a(t)$ is thus given by

$$
\frac{d a}{d t}=-\frac{d x}{d t} \frac{1}{1+1.25 a^{2}\left(B-1.25 a^{3}\right)^{-2 / 3}} .
$$

As shown by Kao et al., ${ }^{13,14}$ the oxidation of non-planarstructured Si must take into account the influence of stress at the $\mathrm{Si} / \mathrm{SiO}_{2}$ interface. Indeed, as the volume of grown oxide is larger than the initial volume of $\mathrm{Si}$, the material should expand. As a result, the newly formed oxide pushes the old one which rearranges itself through viscous flow. The structure relaxes towards equilibrium according to the mechanical properties of the oxide which are characterized by fluid deformations. Following Kao et al., ${ }^{13,14}$ two types of stress are generated that retard the oxidation process. One is the normal compressive stress $\sigma$ generated at the $\mathrm{Si} \mathrm{NC/SiO}$ interface and the other one is the tensile stress $P$ (hydrostatic pressure) generated in the oxide shell [see Fig. 6(a)].

For 3D structures, the normal stress at the $\mathrm{Si} \mathrm{NC}$ interface is given by ${ }^{15,16}$

$$
\sigma=-4 \eta \beta\left(\frac{1}{a^{3}}-\frac{1}{b^{3}}\right),
$$

where $\eta$ is the viscosity and $\beta$ is the velocity constant, which is a function of the oxide velocity at the interface. Based on the work of Omachi et al. ${ }^{16}$ we take the following sign convention for stress: positive for tension and negative for compression. The effect of this normal stress is to reduce the surface reaction rate $\left(k_{s}\right)$ by adding to activation energy the extra work which has to be carried out by the expanding oxide, ${ }^{13-16}$

$$
k_{s}=k_{s o} \exp \left(\frac{\sigma \Omega}{k T}\right),
$$

with $\Omega$ the volume expansion and $k_{s o}$ the stress-free value of $k_{s}$.
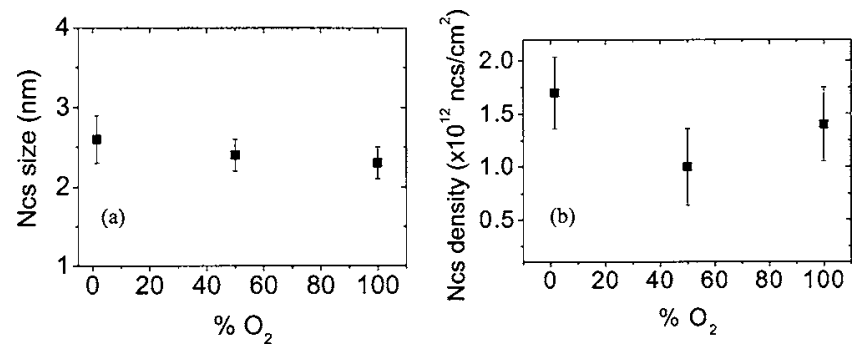

FIG. 7. Evolution of (a) the $\mathrm{NC}$ mean radius and (b) $\mathrm{NC}$ density vs the $\mathrm{O}_{2}$ content, as measured on plan-view PEELS-STEM images. The samples have been implanted at $1 \mathrm{keV}$ with a dose of $2 \times 10^{6} \mathrm{~cm}^{-2}$, annealed under $\mathrm{N}_{2}$ during $30 \mathrm{~min}$ at $1050{ }^{\circ} \mathrm{C}$ and under $\mathrm{N}_{2}$-diluted $\mathrm{O}_{2}$ with $1.5 \% \mathrm{O}_{2}, 50 \%$ $\mathrm{O}_{2}$, and $100 \% \mathrm{O}_{2}$ at $900{ }^{\circ} \mathrm{C}$ for $30 \mathrm{~min}$.

For planar oxidation, $k_{s o}$ varies with the oxygen partial pressure. ${ }^{17,32,33}$ Nevertheless, the NC population is found the same in the experimental error bars (in average size and aerial density) when oxidizing under $1.5 \%$ of $\mathrm{O}_{2}$ and $100 \%$ $\mathrm{O}_{2}$ (see Fig. 7). The oxidation of the particles is therefore independent of the $\mathrm{O}_{2}$ content. As a consequence, $k_{s o}$ has been taken here independent of the oxygen partial pressure. The parameter $\Omega$ has the physical significance of the reaction jump volume in the $\mathrm{Si}$ to $\mathrm{SiO}_{2}$ transition. The model states here that the oxidizing species need to have enough energy to move the newly formed oxide against the normal force field $\sigma$. The energy required in a unit reaction is the product of the reaction jump volume $\Omega$ and $\sigma$. Initially, $\Omega$ was taken equal to $\Omega_{\mathrm{SiO}_{2}}-\Omega_{\mathrm{Si}}=25 \AA^{3},{ }^{13-16}$ while Sutardja et al. ${ }^{25}$ and $\mathrm{Su}-$ tardja and Oldman ${ }^{26}$ argued that a unit reaction involves the breaking of one $\mathrm{Si}-\mathrm{Si}$ bond and the attachment of a bridging oxygen atom between the two $\mathrm{Si}$ atoms. In this case, $\Omega$ must be close to $12.5 \AA^{3}$, the difference between the volume of $\mathrm{Si}-\mathrm{O}$ and $\mathrm{Si}$. In our model, these two cases have been considered. This normal stress makes the reaction at the silicon NC surface more difficult and affects the surface reaction rate which decreases as the normal stress compressively increases.

The hydrostatic pressure in the oxide volume $(P)$ is given by ${ }^{16}$

$$
P=4 \eta \beta \frac{1}{b^{3}} .
$$

This stress is created in the bulk of the old oxide which is stretched and being pushed out and is tensile for convex surfaces. The diffusivity $D$ and the solubility $C^{*}$ of the oxidant are increased by tension while it is the opposite for the viscosity $\eta,{ }^{13,14,16}$

$$
\begin{aligned}
& D=D_{0} \exp \left(\frac{P V_{a}}{k T}\right), \\
& C^{*}=C_{0}{ }^{*} \exp \left(\frac{P V_{s}}{k T}\right), \\
& \eta=\eta_{0} \exp (-\alpha P),
\end{aligned}
$$

where $D_{0}, C_{0}{ }^{*}$, and $\eta_{0}$ are, respectively, the zero-pressure diffusivity, solubility, and viscosity. $V_{a}$ and $V_{s}$ are the activation volumes of diffusivity and solubility. $\alpha$ is an empirical 
parameter. We assume here the pressure-dependent oxide viscosity model proposed by Kao et al. ${ }^{13,14}$ As the tensile stress increases the $\mathrm{O}_{2}$ diffusivity and solubility increase while the viscosity decreases. Then, the oxidant transport and the viscous flow are enhanced comparing to zero-pressure conditions. The two stresses $\sigma$ and $P$ are functions of viscosity which has a strong temperature dependence. Therefore, the normal and hydrostatic stresses are both higher at low temperatures for which the viscosity is much larger and it is more difficult for the oxide to flow. By taking into account these stress effects, the oxidation rate can be written as

$$
\frac{d x}{d t}=\frac{C_{1} \exp (\sigma \Omega / k T)}{1+\exp (\sigma \Omega / k T)\left\{\left(a^{2} / b^{2}\right) C_{2}+[a(b-a) / b] C_{3}\right\}},
$$

with

$$
\begin{aligned}
& C_{1}=C_{10} \exp \left(\frac{P V_{s}}{k T}\right) \quad \text { and } C_{10}=\frac{C_{0}{ }^{*} k_{s o}}{N}=\left(\frac{B}{A}\right)_{\mathrm{DG}} \\
& C_{2}=C_{20}=\frac{k_{s o}}{h} \\
& C_{3}=\frac{C_{30}}{\exp \left(P V_{a} / k T\right)} \quad \text { and } C_{30}=\frac{k_{s o}}{D_{0}}=2\left(\frac{B}{A}\right)_{\mathrm{DG}} / B_{\mathrm{DG}}
\end{aligned}
$$

$C_{10}$ and $C_{30}$ are deduced from the linear and parabolic constants $(B / A)_{\mathrm{DG}}$ and $B_{\mathrm{DG}}$ of the $1 \mathrm{D}$ Deal and Grove (DG) oxidation model $^{17}$ and depend only on the temperature and $\mathrm{Si}$ orientation. We considered here for the dots a (111) orientation even if they are, in fact, randomly oriented. Indeed, for this orientation the oxidation velocity ranges in between the velocity for (110) orientation, which is the fastest and the one for (100) orientation, which is the slowest. $C_{20}$ is more problematic to evaluate as depending on $h$, the gas-phase mass transfer coefficient, which is a function of the furnace configuration. Nevertheless, in our calculation, the term depending on $C_{2}$ is always negligible, when considering classical values for $h$, taken from the literature. ${ }^{15,17}$

The time evolution of the oxidation rate is solved by means of a Runge-Kutta method. The initial values of $a$ and $b$ are taken from the experiment: $a_{0}=1.5 \mathrm{~nm}$ is the $\mathrm{NC}$ mean radius for the reference (nonoxidized) sample, as measured on the images in Fig. 1. Our system differs from those previously studied in the literature because the NCs are embedded within $\mathrm{SiO}_{2}$ and not deposited on top of it. Indeed, in our case a shell of $\mathrm{SiO}_{2}$ surrounds the NCs before the beginning of the oxidation process and this shell is larger than the NC radius itself. This oxide shell is anisotropic in dimension as the average distance between the NCs (lateral distance, $d$ ) can be different from the distance of the precipitates to the free surface (perpendicular distance, $R_{p}$ ), see Fig. 6(b). The average distance $(d)$ between the precipitates can be calculated from the NC density and ranges between 4 and $6 \mathrm{~nm}$ following the model considered (hexagonal-type compact stacking or a classical cubic one). This leads to an oxide shell $b_{0_{1}}=d-a_{0}$ ranging from 3 to $5.5 \mathrm{~nm}$ [see Fig. 6(b)]. On the other hand the distance of the NCs to the surface (perpendicular distance) can be measured on XTEM images and is
$b_{0_{2}}=R_{p}=4.5 \pm 0.5 \mathrm{~nm}$. This value ranges in between the two values found for $b_{0}$ when considering lateral distances. Therefore the anisotropy of the system is not very important $(1.5 \pm 0.5 \mathrm{~nm})$. Finally, the impact of the initial value of the oxide shell $\left(b_{0}\right)$ on the simulation has been tested and we have seen that a decrease of $b_{0}$ leads to an increase of the viscosity (and inversely) to fit the experimental evolution. Anyway, these viscosity values always range in the expected ones at this temperature. ${ }^{30}$ We have taken in our model $x_{0}$ $=b_{0}-a_{0}$ on the order of the control gate oxide thickness at $t=0$, and therefore $b_{0}=4.5 \mathrm{~nm}$ (perpendicular distance), as measured in the XTEM images in Fig. 4.

Omachi et al. ${ }^{16}$ used the activation volumes of solubility and diffusivity, $V_{s}$ and $V_{a}$, respectively, as fitting parameters. For wet oxidation, Kao et al. ${ }^{13,14}$ have shown that $V_{s}$ must be of the same order of magnitude as the molecular volume of $\mathrm{H}_{2} \mathrm{O}$. In this direction, we have considered $V_{s}$ of the order of magnitude of the molecular volume of $\mathrm{O}_{2}$, i.e., $20 \AA^{3}{ }^{34}$ for dry oxidation. Concerning $V_{a}$, a large range of values can be found in the literature, from 75 to $600 \AA^{3}$. $^{16,24,25}$ These values are deduced by experimental data fitting. By using $V_{a}$ in the 75-600 $\mathrm{A}^{3}$ range, our simulation results indicate that this parameter has no significant impact on the oxidation rate. As a consequence, the zero-pressure viscosity, $\eta_{0}$, and the pressure coefficient for viscosity, $\alpha$, are the only fitting parameters needed in our model for describing the thermal oxidation of NCs.

Also, by considering these input values, we obtain $\exp (\sigma \Omega / k T)\left\{\left(a^{2} / b^{2}\right) C_{2}+[a(b-a) / b] C_{3}\right\} \ll 1, \quad$ i.e., $\quad 1 / k_{s}$ $\gg a^{2} / b^{2} h+a(b-a) / b D$. In other words, the oxidation process does not depend on the diffusion coefficient and is only a function of $k_{s}$, the surface reaction rate. The oxidation is therefore reaction limited, as it is the case in planar oxidation for thin oxides. ${ }^{17}$

Under this condition, the expression of the oxidation rate can be simplified to

$$
\frac{d x}{d t}=C_{10} \exp \left(\frac{P V_{s}}{k T}\right) \exp \left(\frac{\sigma \Omega}{k T}\right) .
$$

\section{COMPARISON OF THEORY AND EXPERIMENTS}

Concerning the evolution of the $\mathrm{NC}$ mean radius during oxidation, as mentioned in Sec. III, we observe that the size of the NCs decreases and saturates when increasing the oxidation time. This evidences that the oxidation rate slows down as the silicon nanocluster radius becomes smaller, i.e., that we have a self-limited oxidation process. In the case of $\Omega=25 \AA^{3}$, we obtain a good agreement between our model and the experimental data [see Fig. 2(a) in solid line] for a viscosity of $\eta_{0}=7 \times 10^{14}$ poises and for $\alpha=1.5 \times 10^{-8} \mathrm{~Pa}^{-1}$, i.e., of the order of magnitude of the one proposed in Refs. 13 and 16 . When taking $\Omega=12.5 \AA^{3}$, the model fits with the experimental results for a value of viscosity of $3 \times 10^{15}$ poises [see Fig. 2(a) in dashed line]. These values of viscosity are very close to the one found by Fargeix and Ghibaudo $\left(1.5 \times 10^{15}\right.$ poises $)$ for dry oxides. ${ }^{30}$ While the value taken for $\alpha$ has no strong impact on calculation, this is not the case for 


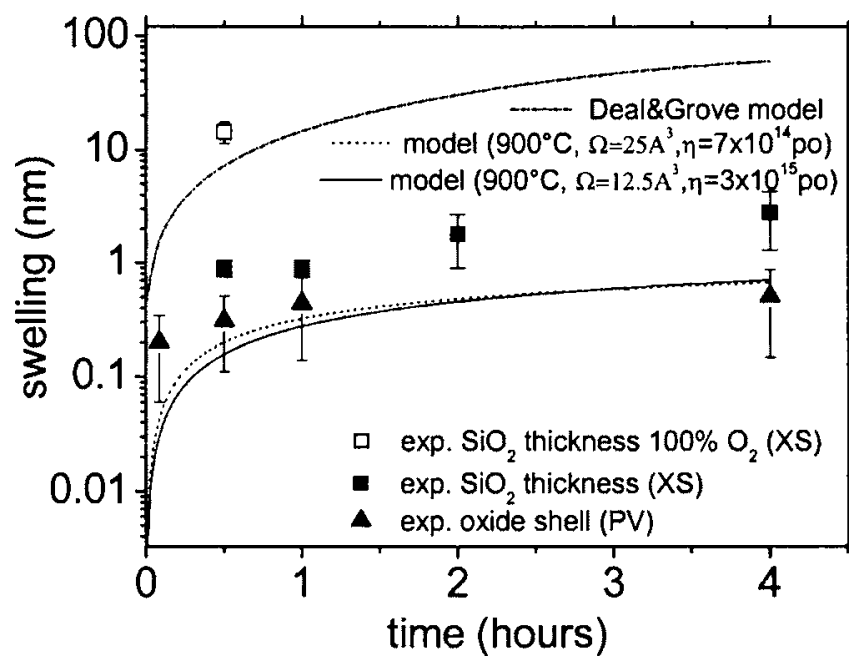

FIG. 8. Experimental evolution vs annealing time of the swelling with respect to the nonoxidized sample of the whole $\mathrm{SiO}_{2}$ layer measured in XTEM (plain squares for $1.5 \% \mathrm{O}_{2}$ and empty squares for $100 \% \mathrm{O}_{2}$ ) and of the thickness increase of the $\mathrm{SiO}_{2}$ shell generated by the $\mathrm{Si} \mathrm{NC}$ oxidation, as deduced from plan-view measurements (up triangles). In the dot-dashed line is plotted the model predictions for planar oxidation (1D Deal and Grove model) and in the solid and dashed lines our model results for $3 \mathrm{D}$ oxidation (for, respectively, $\Omega=25 \AA^{3}$ and $\Omega=12.5 \AA^{3}$ ).

the zero-pressure viscosity $\left(\eta_{0}\right)$ at low temperatures; the smaller is the viscosity, the faster is the oxidation. As a consequence, the only parameter that affects oxidation is $\eta_{0}$. The agreement between our experimental data and simulation for realistic values of the viscosity renders our model credible.

The oxide shell dimension $(b-a)$ can be deduced from the experiment by subtracting the average volume of the NCs before and after each step of oxidation, calculated from the experimental mean radius and taking into account the corresponding volume expansion. The evolution of this shell dimension is plotted in Fig. 8 with triangle symbols. We observe a good agreement between the shell values predicted by our model (Fig. 8, solid and dashed lines following the value of $\Omega$ ) and the experimental values. As already emphasized in Refs. 16, 22, 23, and 35, the oxidation of 3D NCs is slower than the one predicted by the classical Deal and Grove model for a planar interface, as plotted in the dotdashed line in Fig. 8. ${ }^{17}$ This theoretical evolution even underestimates the oxidation rate which is enhanced for thin oxides (below $25 \mathrm{~nm}$ ). ${ }^{36}$ We can also notice that, for oxidation times larger than 5 min the expansion of the whole $\mathrm{SiO}_{2}$ layer (square symbols in Fig. 8), deduced from Fig. 5, is much larger than these shell values (triangle symbols in Fig. 8). This discrepancy is due to the $\mathrm{SiO}_{2} / \mathrm{Si}$ interface oxidation already mentioned in Sec. III. Anyway, this interface oxidation is several times smaller than the one predicted by the planar oxidation Deal and Grove model (dot-dashed line). ${ }^{17}$ This can be explained by the percentage of $\mathrm{O}_{2}$ which is $1.5 \%$ instead of $100 \%$. Indeed, if there is no effect of the $\mathrm{O}_{2}$ pressure on the $\mathrm{NC}$ reaction rate because the oxidation process is mainly limited by the stress effects, this is not the case for the oxidation rate of the $\mathrm{SiO}_{2} / \mathrm{Si}$ substrate interface. By comparison, the oxide swelling for the sample annealed with $100 \% \mathrm{O}_{2}$ at $900{ }^{\circ} \mathrm{C}$ for $30 \mathrm{~min}$ (open square in Fig. 8) is $10 \pm 0.5 \mathrm{~nm}$ larger than the one for the $1.5 \% \mathrm{O}_{2}$ at this ther-

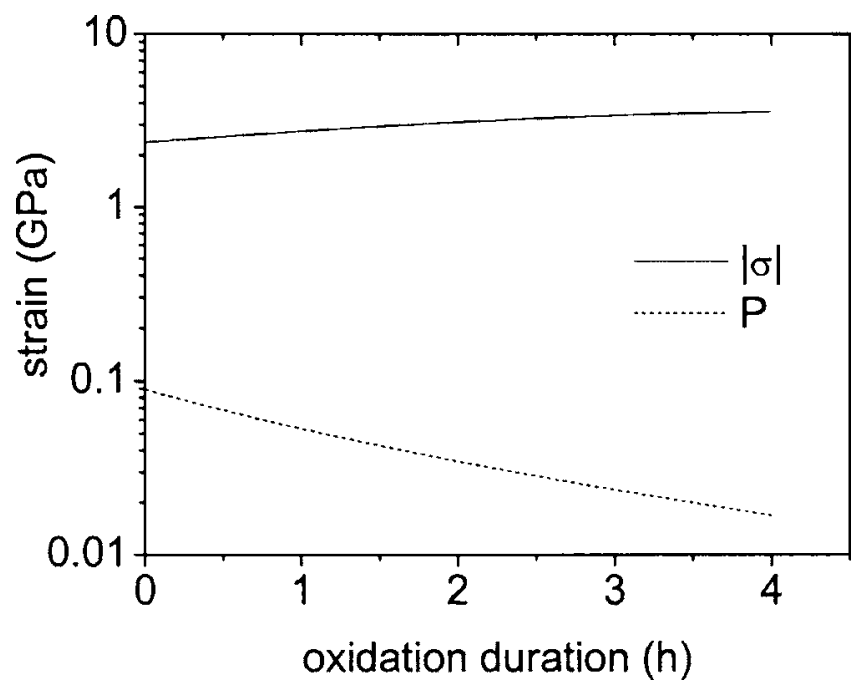

FIG. 9. Evolution of compressive stress $\sigma$ (in absolute value) and tensile stress $P$ vs the annealing time for $\Omega=25 \AA^{3}$.

mal budget. This expansion is even larger than the one expected by the Deal and Grove theory, as predicted by Massoud et al. ${ }^{36}$

In Fig. 9, we have plotted the compressive normal stress $\sigma$ at the interface of the NCs (in absolute value) and the tensile stress in the oxide bulk (hydrostatic pressure) $P$ in the bulk oxide predicted by the model during oxidation. When increasing the oxidation duration, $\sigma$ increases in absolute value, leading to a decrease of the reaction rate $k_{s}$ and therefore a retardation of the oxidation process. On the other hand, the tensile stress in the volume, $P$, decreases during oxidation, leading to a decrease of the $\mathrm{O}_{2}$ diffusivity and solubility, even if both of them remain larger than the values at zero pressure. In particular, the decrease of the solubility during oxidation contributes to the retardation of the oxidation process. The decrease of the hydrostatic pressure during oxidation also leads to an increase of the viscosity that increases the normal strain at the interface (in absolute value) and therefore contributes also to the retardation of the oxidation process.

A good agreement between our model and the experimental evolution is obtained by considering both the effect of the normal stress at the interface $(\sigma)$ and the stress in the volume $(P)$. When considering only one of these two stresses the model fails in describing the experimental evolution. When taking into account $P$ only while the oxidation rate is several times faster than when taking into account both $P$ and $\sigma$. For $\sigma$ only, a quasilinear evolution of the NC radius is found and fails in fitting the experimental evolution, whatever the considered viscosity and volume expansion $(\Omega)$.

For the considered viscosity, the values of the compressive stress at the interface and the tensile stress in the oxide volume are of the order of some $10^{9}$ and $10^{8} \mathrm{~Pa}$, respectively, and this, for the two values considered for $\Omega$. These stress values are of the order of magnitude of the ones obtained by Dalla Torre et al. by using Monte Carlo calculation of the oxidation of very small $\mathrm{Si}$ NCs. ${ }^{34}$

We carried out all the calculations in this model assuming Newtonian flow of the oxide but, as mentioned in Sec. 


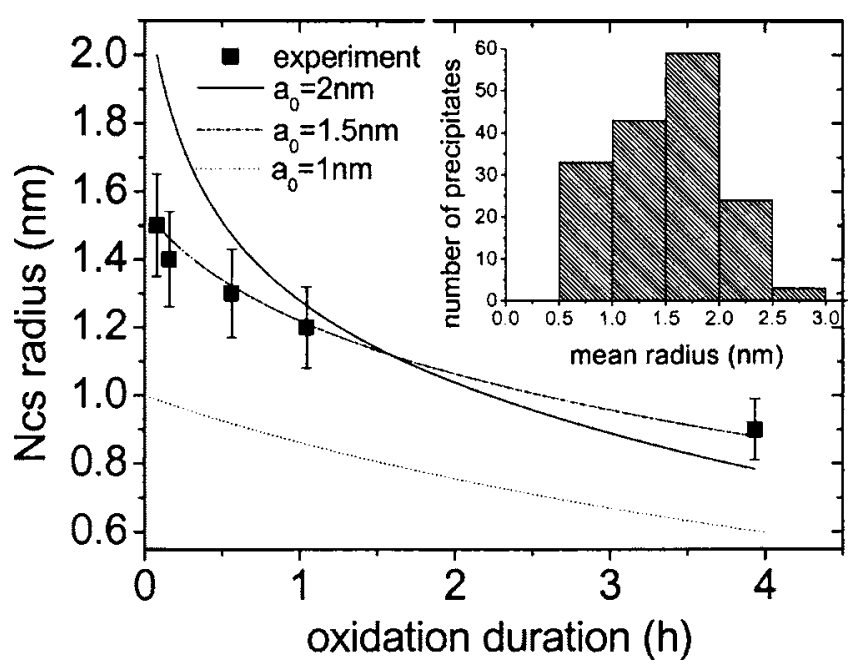

FIG. 10. Simulation of the evolution of the NC mean radius during oxidation for the different classes of size $\left(a_{0}=1 \mathrm{~nm}, a_{0}=1.5 \mathrm{~nm}\right.$, and $\left.a_{0}=2 \mathrm{~nm}\right)$ encountered in the initial size histogram, shown in the inset, of the reference sample (nonoxidized). The simulations have been carried out with $\Omega$ $=12.5 \AA^{3}$ and $\eta_{0}=1.5 \times 10^{15}$ poises.

IV, it was observed that at high temperature the flow of glasses is nonlinear at high stresses. ${ }^{24-26,28}$ The stress level is here larger than that critical stress for nonlinear behaviors $\left(\sigma_{c}=10^{8} \mathrm{~Pa}\right)$, suggesting that our model is limited and that the plastic flow should be considered. Nevertheless, this critical stress value, used in the actual plastic models, is measured for silica glass for which the viscosity and the glass transition temperature are different from dry thermal $\mathrm{SiO}_{2}{ }^{37}$ It is therefore difficult to take this value as an absolute threshold. In addition, the stress values that we obtained are in good agreement with those measured by Raman for NC ion beam synthesized in $\mathrm{SiO}_{2}(\sim 1 \mathrm{GPa}),{ }^{38}$ and this stress level is still lower than the threshold value for the fracture of a Si wafer (10-25 GPa). ${ }^{39}$

A last point to clarify lies in the important decrease of the NC aerial density, which falls down from $2.2( \pm 0.4)$ $\times 10^{12}$ to $2.5( \pm 0.5) \times 10^{11} \mathrm{~cm}^{-2}$, as experimentally observed on Fig. 2(b). Even if the average diameter of the NCs decreases down to $2 \pm 0.2 \mathrm{~nm}$, this value is still larger than the visibility threshold in the PEELS-STEM images, which lies around $1 \mathrm{~nm}$. Nevertheless, the NCs are size distributed (see inset of Fig. 10 for the nonoxidized sample) and the simulation of Fig. 2(a) (or reported in the dot-dashed line in Fig. 10) concerns only the NCs having the average size of the population $(1.5 \mathrm{~nm})$. The NCs initially larger than the average size, for instance, those having a radius of $2 \mathrm{~nm}$, are shrinking faster as their initial oxidation velocity is higher (see Fig. 10 in solid line). For this reason, after $100 \mathrm{~min}$ of annealing, their size is smaller than the one reached by the NCs starting with a radius of $1.5 \mathrm{~nm}$.

Anyway, even if shrinking faster, they are still larger than the visibility limit at the end of the oxidation. On the other hand, around $50 \%$ of the NCs for the nonoxidized sample are smaller than the average size (see inset of Fig. 10). The simulation of the oxidation of precipitates having 1 $\mathrm{nm}$ in diameter is also shown in Fig. 10 (dashed line). After 240 min of annealing, this class of NCs has an average di- ameter of around $1.2 \mathrm{~nm}$, i.e., close to the visibility limit. We can consider therefore that $50 \%$ of the NCs have disappeared during the oxidation annealing. This dissolution does not explain the decrease of $90 \%$ in density observed in Fig. 2(b) but one has to take into account that during annealing the NCs naturally encompass a competitive growth called Ostwald ripening ${ }^{40}$ where the $\mathrm{NC}$ density naturally decreases. A study of the evolution of the NC population, when annealing in this range of temperature under $\mathrm{N}_{2}$ only, shows a natural decrease of the NC density of $40 \%$ while the mean radius only slightly increases, due to a nonconservative ripening process. The important decrease of the density as observed in Fig. 2(a) can be therefore attributed to the cumulative effect of these two processes.

\section{CONCLUSION}

In conclusion, thermal treatments in $\mathrm{N}_{2}$-diluted $\mathrm{O}_{2}$ at a temperature below the viscoelastic temperature of $\mathrm{SiO}_{2}$ $\left(950{ }^{\circ} \mathrm{C}\right)$ appear to be a powerful way for manipulating the size distribution and surface density of 2D arrays of NCs embedded in thin $\mathrm{SiO}_{2}$ films. Our experiments performed at $900{ }^{\circ} \mathrm{C}$ in $1.5 \% \mathrm{O}_{2}$ reveal that the $\mathrm{NC}$ mean size, density, and surface fraction significantly decrease with annealing duration, while the oxidation rate of the NCs slows down with time and stabilizes after $1 \mathrm{~h}$ annealing, thus indicating a selflimiting oxidation process. The $\mathrm{Si}$ substrate $/ \mathrm{SiO}_{2}$ interface is also oxidized but at a rate slower than the one predicted for planar oxidation. This discrepancy is due to the limited $\mathrm{O}_{2}$ content used in our experiments. The effect of thermal oxidation on the Si NC size can be predicted by means of an extended spherical Deal-Grove model taking into account a stress-induced retardation process. The oxidation process is reaction limited and both (a) normal stress at the Si NC interface that retards the reaction rate constant $k_{s}$ and (b) tensile stress in the bulk oxide that modifies the oxide viscosity and oxygen solubility in the oxide must be considered. The reaction rate being strongly limited by these stress effects, the $\mathrm{O}_{2}$ percentage has no effect on the NC oxidation itself. The stress values required in our 3D model are smaller than the threshold for Si wafer fracture, but high enough for suggesting that possible effects of plasticity occur during $\mathrm{SiO}_{2}$ deformation. This last phenomenon is under investigation and will be discussed in detail later together with the thermal oxidation of NCs at temperatures above the viscoelastic point. Finally, the electrical properties of the NC gate stacks herein reported have been studied and will be published in the close future.

\section{ACKNOWLEDGMENTS}

The authors would like to thank V. Soncini from ST Microelectronics Agrate for the oxidized wafers, A. Agarwal from Axcelis Technologies Inc. for the implantations, and $\mathbf{M}$. Tencé and C. Colliex from LPS Orsay for PEELS-STEM images. The authors also gratefully acknowledge C. Krzeminski from IEMN Lille for fruitful discussions on the kinetics of oxidation. 
${ }^{1}$ S. Tiwari, F. Rana, H. I. Hanafi, A. Hartstein, E. F. Crabbé, and K. Chan, Appl. Phys. Lett. 68, 1377 (1996).

${ }^{2}$ G. Ammendola et al., J. Vac. Sci. Technol. B 20, 2075 (2002).

${ }^{3}$ Y. C. King, T. J. King, and C. Hu, IEEE Trans. Electron Devices ED-48, 696 (2001)

${ }^{4}$ H. I. Hanafi, S. Tiwari, and I. Khan, IEEE Trans. Electron Devices 43, 1553 (1996).

${ }^{5}$ P. Normand, D. Tsoukalas, E. Kapetanakis, J. van den Berg, D. G. Armour, J. Stoemenos, and C. Vieu, Electrochem. Solid-State Lett. 1, 88 (1998).

${ }^{6}$ P. Normand et al., Nucl. Instrum. Methods Phys. Res. B 178, 74 (2001).

${ }^{7}$ C. Bonafos, M. Carrada, N. Cherkashin, H. Coffin, D. Chassaing, G. Ben Assayag, and A. Claverie, J. Appl. Phys. 95, 5696 (2004).

${ }^{8}$ P. Normand et al., Appl. Phys. Lett. 83, 168 (2003).

${ }^{9}$ P. Dimitrakis et al., Solid-State Electron. 48, 1511 (2004).

${ }^{10}$ H. Coffin et al., Mater. Res. Soc. Symp. Proc. 830, D6.6 (2005).

${ }^{11}$ E. P. EerNisse, Appl. Phys. Lett. 30, 290 (1977).

${ }^{12}$ E. P. EerNisse, Appl. Phys. Lett. 35, 8 (1979).

${ }^{13}$ D. B. Kao, J. P. McVittie, W. D. Nix, and K. C. Saraswat, IEEE Trans Electron Devices ED-35, 25 (1988).

${ }^{14}$ D. B. Kao, J. P. McVittie, W. D. Nix, and K. C. Saraswat, Tech. Dig. - Int Electron Devices Meet. 1985, 388.

${ }^{15}$ Y. Chen, Microelectron. Eng. 57-58, 897 (2001).

${ }^{16} \mathrm{~J}$. Omachi, R. Nakamura, K. Nishiguchi, and S. Oda, Mater. Res. Soc. Symp. Proc. 638, F531 (2001).

${ }^{17}$ B. E. Deal and A. S. Grove, J. Appl. Phys. 36, 3770 (1965).

${ }^{18}$ C. Jeanguillaume and C. Colliex, Ultramicroscopy 28, 252 (1989).

${ }^{19}$ G. B. Assayag, C. Bonafos, M. Carrada, A. Claverie, P. Normand, and D. Tsoukalas, Appl. Phys. Lett. 82, 200 (2003).

${ }^{20}$ T. Müller et al., Appl. Phys. Lett. 85, 2373 (2004).
${ }^{21}$ C. Bonafos et al., Mater. Res. Soc. Symp. Proc. 830, D5.2 (2005)

${ }^{22}$ H. I. Liu, D. K. Biegelsen, N. M. Johnson, F. A. Ponce, and R. F. W. Pease, J. Vac. Sci. Technol. B 11, 2532 (1993).

${ }^{23}$ K. C. Scheer et al., J. Appl. Phys. 93, 5637 (2003).

${ }^{24}$ V. Senez, D. Collard, B. Baccus, M. Brault, and J. Lebailly, J. Appl. Phys. 76, 3285 (1994).

${ }^{25}$ P. Sutardja, W. Oldman, and D.-B. Kao, Tech. Dig. - Int. Electron Devices Meet. 1987, 264

${ }^{26}$ P. Sutardja and W. Oldman, IEEE Trans. Electron Devices ED-36, 2415 (1989).

${ }^{27}$ G. Hetherington, K. H. Jack, and J. C. Kennedy, Phys. Chem. Glasses 5, 130 (1964).

${ }^{28}$ C. S. Rafferty and R. W. Dutton, Appl. Phys. Lett. 54, 1815 (1989).

${ }^{29}$ C. S. Rafferty, L. M. Landsberger, R. W. Dutton, and W. A. Tiller, Appl. Phys. Lett. 54, 151 (1989).

${ }^{30}$ A. Fargeix and G. Ghibaudo, J. Appl. Phys. 54, 7153 (1983).

${ }^{31}$ E. B. Dane and F. Birch, J. Appl. Phys. 9, 669 (1938).

${ }^{32}$ N. Lie, R. Razouk, and B. E. Deal, J. Electrochem. Soc. 129, 2828 (1982).

${ }^{33}$ A. Reisman, E. H. Nicollian, C. K. Williams, and C. J. Merz, J. Electron. Mater. 16, 45 (1987).

${ }^{34}$ J. Dalla Torre, et al. J. Appl. Phys. 92, 1084 (2002).

${ }^{35}$ R. Okada and S. Lijima, Appl. Phys. Lett. 58, 1662 (1991).

${ }^{36}$ H. Z. Massoud, J. D. Plummer, and E. A. Irene, J. Electrochem. Soc. 132, 2685 (1985).

${ }^{37}$ P. P. Donnadieu, O. Jaoul, and M. Kleman, Philos. Mag. A 52, 5 (1985).

${ }^{38}$ A. Wellner, V. Paillard, N. Cherkashin, C. Bonafos, H. Coffin, B. Schmidt, K. H. Heinig, and A. Claverie, J. Appl. Phys. 94, 5639 (2003).

${ }^{39}$ J. Grisolia, G. B. Assayag, B. de Mauduit, A. Claverie, R. E. Kroon, and J. H. Neethling, Mater. Res. Soc. Symp. Proc. 681, I3.2.1 (2001).

${ }^{40}$ C. Bonafos et al., Nucl. Instrum. Methods Phys. Res. B 178, 17 (2001). 